\title{
Friction Stir Welding of ODS and RAFM Steels
}

\author{
ZHENZHEN YU, ZHILI FENG, DAVID HOELZER, LIZHEN TAN, \\ and MIKHAIL A. SOKOLOV
}

\begin{abstract}
Advanced structural materials such as oxide dispersion strengthened steels and reduced-activation ferritic/martensitic steels are desired in fusion reactors as primary candidate materials for first wall and blanket structures, due to their excellent radiation and high-temperature creep resistance. However, their poor fusion weldability has been the major technical challenge limiting practical applications. For this reason, solid-state friction stir welding (FSW) has been considered for such applications. In this work, the effect of FSW parameters on joining similar and dissimilar advanced structural steels was investigated. Scanning electron microscopy and electron backscatter diffraction methods were used to reveal the effects of FSW on grain size, micro-texture distribution, and phase stability. Hardness mapping was performed to evaluate mechanical properties. Post weld heat treatment was also performed to tailor the microstructure in the welds in order to match the weld zone mechanical properties to the base material.
\end{abstract}

DOI: $10.1007 / \mathrm{s} 40553-015-0054-9$

(C) ASM International (ASM) and The Minerals, Metals \& Materials Society (TMS) 2015

\section{INTRODUCTION}

THE future fusion reactors will require utilization of advanced structural materials that must safely sustain the extremely hostile environment, e.g., intense heat fluxes, significant cyclic thermomechanical stresses, intense fluxes of high-energy neutrons and electromagnetic radiation, and reactive chemicals. These structural materials typically feature highly complex and unique microstructures tailored for high-performance properties.

For example, oxide dispersion strengthened (ODS) steels are likely near-term candidates as fusion structural materials, which exhibit remarkable radiation damage resistance and high-temperature tensile, creep, and fatigue strengths. ${ }^{[1-7]}$ The outstanding performance characteristics of these alloys (e.g., MA956 and 12/14YWT) are attributed to the presence of an ultrahigh density of $\mathrm{Y}-\mathrm{Al} / \mathrm{Ti}-\mathrm{O}$ rich oxide particles produced through carefully engineered and

ZHENZHEN YU, Assistant Professor, formerly with the Materials Science and Technology Division, Oak Ridge National Laboratory, Oak Ridge, TN 37831, is now with the Department of Metallurgical and Materials Engineering, Colorado School of Mines, Golden, CO 80401. ZHILI FENG, Distinguished Ramp;\&D Staff and Group Leader of Materials Processing and Joining, and DAVID HOELZER, LIZHEN TAN, and MIKHAIL A. SOKOLOV, Senior R\&D Staffs, are with the Materials Science and Technology Division, Oak Ridge National Laboratory. Contact e-mail: fengz@ornl.gov

This manuscript has been authored by UT-Battelle, LLC under Contract No. DE-AC05-00OR22725 with the U.S. Department of Energy. The United States Government retains, and the publisher, by accepting the article for publication, acknowledges, that the United States Government retains a non-exclusive, paid-up, irrevocable, world-wide license to publish or reproduce the published form of this manuscript, or allow others to do so, for United States Government purposes. The U.S. Department of Energy will provide public access to these results of federally sponsored research in accordance with the DOE Public Access Plan (http://energy.gov/downloads/doe-public-accessplan).

Manuscript submitted January 1, 2015.

Article published online September 14, 2015 sophisticated mechanical alloying (MA) routes. ${ }^{[7]}$ Take Incoloy Alloy MA956 for example. It is an iron-based ODS ferritic stainless steel with a high level of aluminum for improved corrosion and oxidation resistance. The uniform distribution of fine yttrium oxide dispersion particles contributes to its excellent mechanical strength at elevated temperatures, and yttrium oxide particles are mostly attached to the larger aluminum oxides. ${ }^{[8]}$ ODS alloys must be welded for construction of fusion reactors and other large-scale industry systems. However, these high-performance steels are very difficult, if not impossible, to weld with fusion welding processes such as arc welding, laser welding, and electron beam welding. Bulk melting during fusion welding inevitably destroys the nano-scaled particle distribution by causing the particles to be rejected and aggregated at the solidification front in weld pool. The poor fusion weldability has been the major technical bottleneck limiting the application of the entire family of ODS alloy. Solid-state welding techniques, such as rotary friction welding, ${ }^{[9-11]}$ diffusion welding ${ }^{[12]}$ pulsed electric current sintering bonding, ${ }^{[13]}$ brazing, ${ }^{[14,15]}$ and resistance welding ${ }^{[16]}$ were evaluated on ODS alloys with limited success. However, these welding techniques have their respective drawbacks ranging from restricted applicable workpiece size to low joint strength. For instance, rotary friction welding, one of the most promising techniques for joining the ODS alloys, is limited to welding small, cylindrical parts and cannot be employed for large diameter tubing, let alone various forms of linear plate joints, which are common joint configurations in many high-temperature structures. Hence, new welding technologies must be developed to preserve the oxide dispersion strengthening mechanism in the weld.

Reduced-activation ferritic/martensitic (RAFM) steels containing no elements with high absorption rates of neutrons are considered as the reference first wall and blanket structural material for both International Thermonuclear Experimental Reactor (ITER) test blanket 
modules and future fusion power systems. ${ }^{[7,17-22]}$ While considered to have relatively good weldability, RAFM steels can suffer from welding-induced property degradations caused by phase transformation. ${ }^{[17,22]}$ TIG and EB welding of RAFM F82H (developed in Japan) led to a highly inhomogeneous microstructure in the weld. ${ }^{[22,23]}$ It consisted of several distinctive regions including the fusion zone (FZ), with cast-like microstructures, a coarse-grained heat-affected zone (CG-HAZ), a finegrained HAZ (FG-HAZ), and an over-tempered HAZ (OT-HAZ). The OT-HAZ near the ferrite/austenite phase transformation temperature is the weakest region due to softening. The variations in microstructure in the different regions would also lead to different post irradiation properties and microstructural evolution than those of the base metal. ${ }^{[24]}$ In this regard, welding technologies need to be advanced to eliminate or minimize the property and performance degradations in welded RAFM steels.

More importantly, the fusion reactor will comprise different subsystems and modules that utilize different materials to meet the challenging performance requirements. $^{[18]}$ Dissimilar material joining, i.e.,- -joining vastly different materials such as ODS steels to RAFM steels - is not only essential for successful development of fusion power systems but it also poses an even greater technological challenge in materials joining than joining ODS alloys or RAFM steels alone.

Friction stir welding (FSW) is an innovative solid-state joining process invented in the 1990s by The Welding Institute (TWI) in the UK. Compared to other solid-state joining processes, such as rotary friction welding and inertial welding, FSW is unique in that it enables the advantage of solid-state joining for fabrication of continuous linear welds. During FSW, frictional heating is generated between the rotating tool and the workpiece softening the material and allowing the rotating tool to mechanically stir the material. ${ }^{[25-27]}$ The temperature experienced by the material in the weld region is lower than the melting temperature. Hence, in comparison to conventional fusion welding, an inherent advantage of FSW is that it can prevent defects and property degradation associated with solidification. Some preliminary investigations beginning in 2007 have demonstrated the possibility of using FSW to produce fully consolidated defect-free welds in ODS alloys such as MA956 and PM2000. ${ }^{[7,8,28-30]}$ Therefore, in this work, FSW was utilized to join ODS, RAFM steels, and, in particular, dissimilar metal joining between ODS and RAFM steels. The influence of FSW process conditions on the microstructural features and mechanical properties in the welds was examined and discussed, and a post weld heat treatment (PWHT) was adopted in order to restore the properties in the nugget zone to that in the base material.

\section{EXPERIMENTAL PROCEDURE}

Bead-on-plate FSW experiments were conducted on two different RAFM steels (EUROFER97 with a chemical composition of Fe-9Cr-1W-0.2V-0.07Ta-0.03N-0.1C in wt pet $^{[31]}$ and an experimental RAFM steel with a composition of Fe-9Cr-1.44W-0.18V-0.15Ta-0.0084N-0.12C) to simulate butt welding widely used in the manufacturing of fusion reactors. EUROFER steels were designed for the manufacturing of European breeding reactor blankets. ${ }^{[17]}$ The experimental RAFM has a similar composition to F82H steel originally developed by Japan Atomic Energy Research Institute (JAERI) and JFE Corporation for application in the back wall of nuclear reactors. ${ }^{[31,32]}$ The welding parameters are listed in Table I.

Dissimilar FSW experiments were also conducted between MA956 and EUROFER97. MA956 has a nominal composition of $\mathrm{Fe}-19.7 \mathrm{Cr}-4.6 \mathrm{Al}-0.4 \mathrm{Ti}-0.5 \mathrm{Y}_{2} \mathrm{O}_{3}$ in wt $\mathrm{pct}^{[7,30]}$ and is classified as ferritic stainless steel with good corrosion resistance due to the high $\mathrm{Cr}$ and $\mathrm{Al}$ content. ${ }^{[8,33]}$ One of the MA956's applications is for reactor vessels. An overlay FSW joint was made between MA956 and EUROFER97, Figure 1, in order to simulate welding of subsystems/modules made with the two materials in the chamber of a fusion reactor.

The thicknesses of MA956, EUROFER97, and the experimental RAFM steel sheets are 1, 15, and $8 \mathrm{~mm}$, respectively. In the dissimilar FSW of MA956 to EUROFER97, the MA956 sheet $(\sim 1 \mathrm{~mm}$ thick $)$ is placed on top of the EUROFER 97 plate $(15 \mathrm{~mm}$ thick). The FSW experimental matrix and basic welding conditions are summarized in Table I. Polycrystalline cubic boron nitride (PCBN) FSW tool was chosen as the welding tool material due to its superior hardness and thermal stability. The tool shoulder is about $25.4 \mathrm{~mm}$ in diameter. A conical threaded pin with step-spiral features was used, and the diameter of the pin near the flat shoulder is about $10 \mathrm{~mm}$. The pin height is about $5 \mathrm{~mm}$. A tool tilt angle of $0.5 \mathrm{deg}$ toward the welding direction (i.e., an angle of $98.5 \mathrm{deg}$ between the tool axial and weld direction) was used to assist the material flow behind the tool.

Optical microscopy was performed within the stir zone (SZ), thermo-mechanically affected zone (TMAZ), and HAZ of each weld trial. The sample surface was ground, polished, and etched with a mixture of $30 \mathrm{~mL}$ $\mathrm{HCl}$ and $10 \mathrm{~mL} \mathrm{HNO}_{3}$ for Cases 1 and 2, and Nital for Cases 3 and 4. Electron backscatter diffraction (EBSD) was conducted to examine the effect of FSW on texture

Table I. Parameters Used for FSW Trials on Different Advanced Steels

\begin{tabular}{llccc}
\hline Case No. & Material & Rotation Speed (rpm) & Travel Rate (ipm) & Tool Tilt Angle (deg) \\
\hline 1 & EUROFER97 & 400 & 2 & 0.5 \\
2 & MA956 to EUROFER97 & 400 & 2 & 0.5 \\
3 & Experimental RAFM & 400 & 2 & 0.5 \\
4 & Experimental RAFM & 400 & 2.5 & 0.5 \\
\hline
\end{tabular}




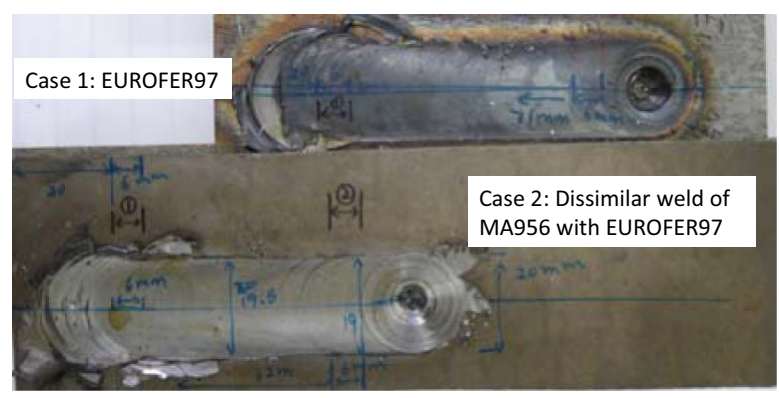

(a)

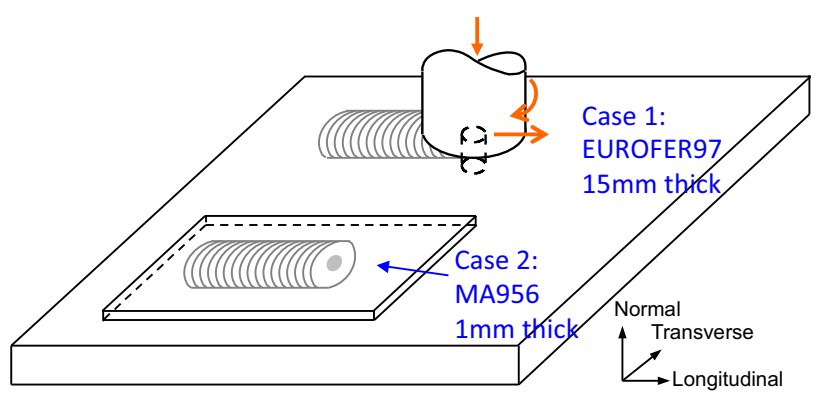

(b)

Fig. 1-(a) Initial FSW trials of Case 1 (FSW of EUROFER97) and Case 2 (dissimilar weld of MA956 with EUROFER97); (b) the schematic drawing of the setup of FSW trials.
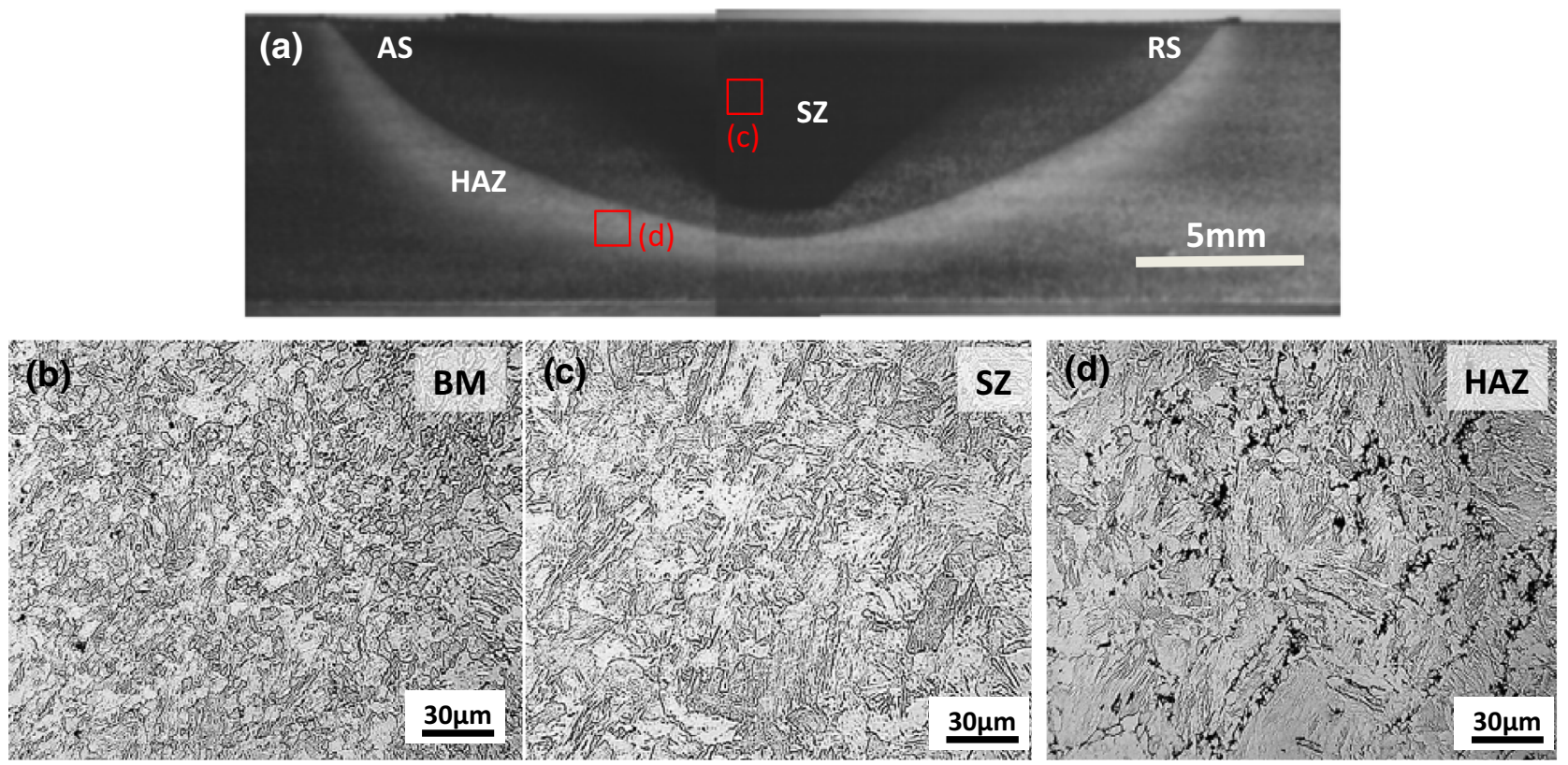

Fig. 2-FSWed experimental RAFM steel (Case 3): (a) Macrograph of the weld cross-section, (b) base metal (BM), (c) stir zone (SZ), and (d) heat-affected zone (HAZ). AS and RS denote advancing and retreating side.

distribution of the RAFM steels. A JEOL 6500F field emission gun (FEG) scanning electron microscope (SEM) equipped with an EBSD detector was used at the Oak Ridge National Laboratory (ORNL). An acceleration voltage of $20 \mathrm{kV}$ was used, and the working distance was set to be $20 \mathrm{~mm}$. A step size of $0.1 \mu \mathrm{m}$ was used to scan the micro-texture distribution. Hardness mapping was also performed on cross-sections of the welds using a LM100AT microhardness tester in order to reveal the effect of FSW on the mechanical property of ODS alloys and RAFM steels. For optical microscopy, the grain size was determined by the linear intercept method. ${ }^{[34]}$

To improve the weld property, PWHTs with various conditions were tested on the experimental RAFM steel welds, to investigate the restoration of the material's mechanical properties. A total of three heat treatment conditions were conducted including (1) tempering at $1033 \mathrm{~K}\left(760{ }^{\circ} \mathrm{C}\right)$ for $0.5 \mathrm{~h}$ followed by quenching, (2) tempering at $1073 \mathrm{~K}\left(800{ }^{\circ} \mathrm{C}\right)$ for $0.5 \mathrm{~h}$ followed by quenching, and (3) re-austenization at $1253 \mathrm{~K}\left(980{ }^{\circ} \mathrm{C}\right)$ for $0.5 \mathrm{~h}$ and quenching, followed by tempering at $1033 \mathrm{~K}\left(760^{\circ} \mathrm{C}\right)$ for $1 \mathrm{~h}$ and air cooling, i.e., the typical heat treatment for the base metal of EUROFER97. The first two conditions are designed to avoid the conventional high-temperature treatment.

\section{RESULTS AND DISCUSSION}

\section{A. FSW of RAFM Steels}

Figure 2 shows a macrograph of the weld cross-section in the experimental RAFM Case 3, and the microstructure within the BM, SZ, and HAZ, respectively. The microstructure in the $\mathrm{BM}$ in Figure 2(b) is tempered martensite. ${ }^{[20,35]}$ Figure 2(c) shows a lath martensitic microstructure present in the SZ indicating that the peak temperature experienced by $\mathrm{SZ}$ was higher than $\mathrm{A}_{3}$ in the 

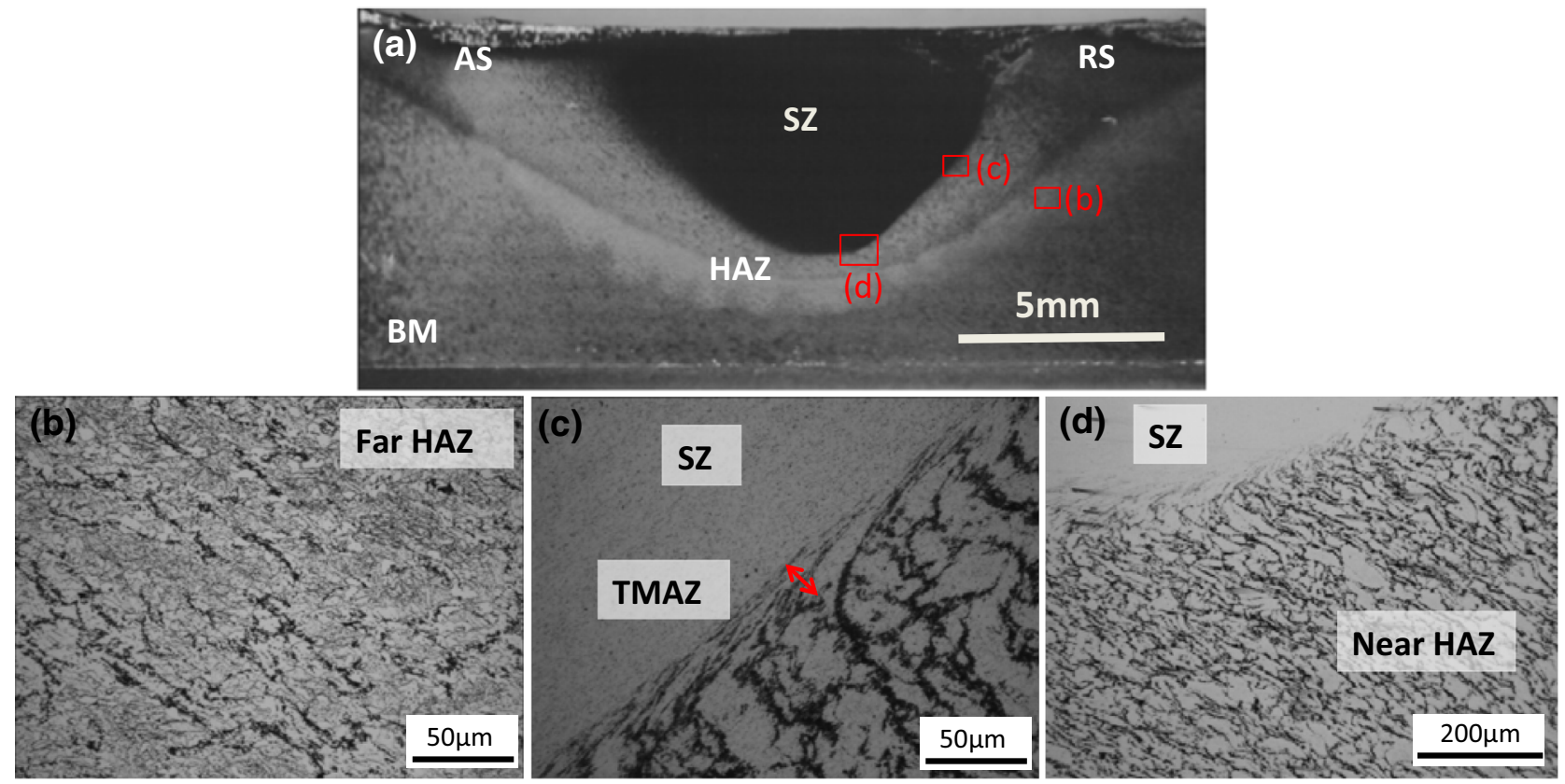

Fig. 3-FSWed experimental RAFM steel (Case 4): (a) Macro- and ( $b$ through $d$ ) micrographs of the weld cross-section. BM, SZ, TMAZ, and HAZ represent base metal, stir zone, thermo-mechanically affected zone, and heat-affected zone, respectively.
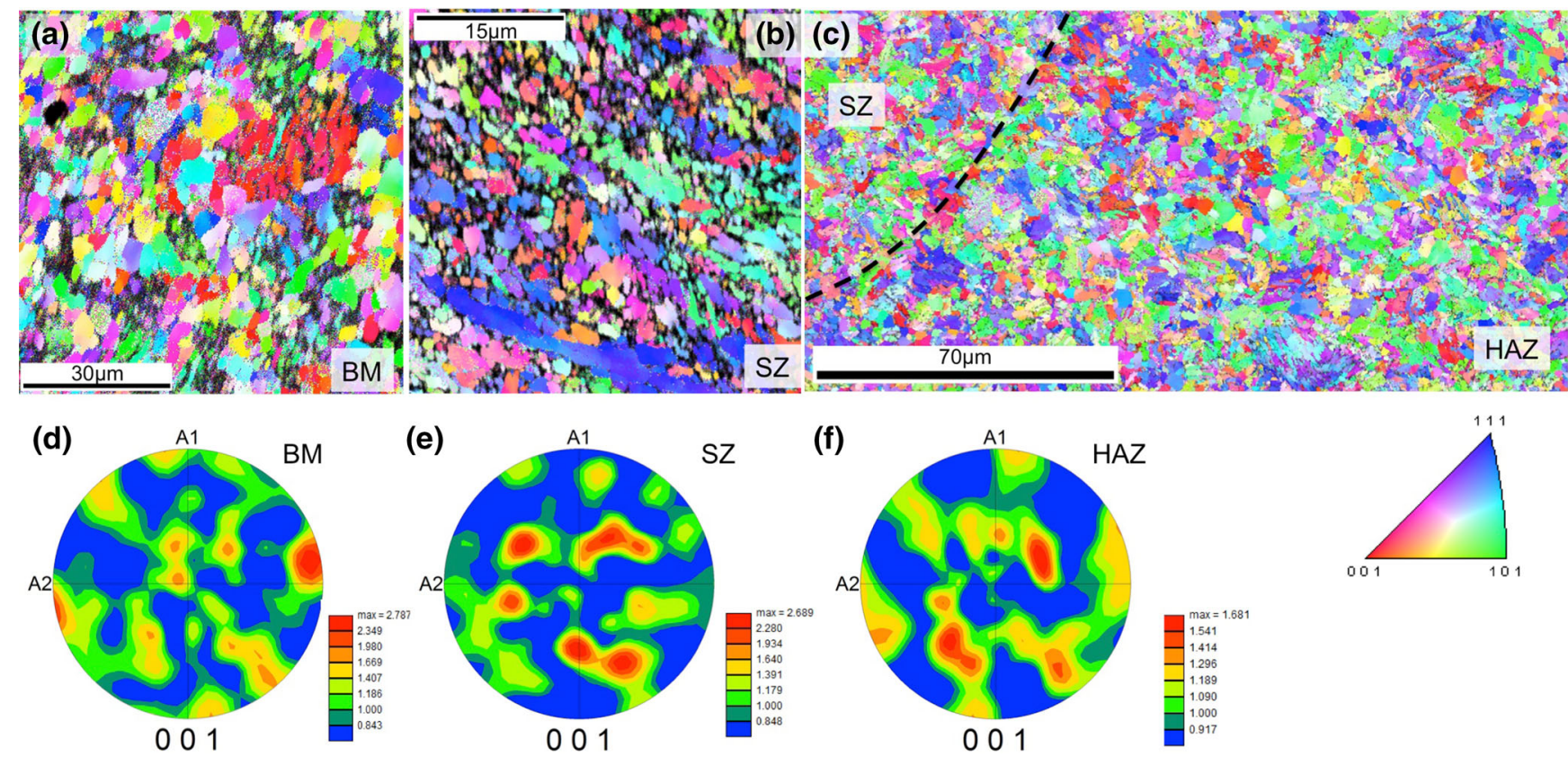

Fig. 4-EBSD results of the base metal $(a)$ and stir zone $(b)$ in advancing side, and the transition from SZ to HAZ $(c)$ on the retreating side of the experimental RAFM steel FSW weld (Case 4), and their corresponding pole figures $(d)$ through $(f)$.

Fe-C phase diagram, which led to a full martensitic transformation. From the SZ to the HAZ, the peak temperature experienced by the material decreases gradually. The HAZ appears to reach a temperature in the intercritical temperature range (between $A_{3}$ and $A_{1}$-lower critical temperature) resulting in phase transformations producing a mixture of martensite, $\mathrm{M}_{23} \mathrm{C}_{6}$ carbide precipitates $^{[20,35]}$ (black dots in Figure 2(d)), and ferrite.
As shown in Figure 3, the microstructures in the FSWed experimental RAFM steel Case 4 were significantly different from the BM. Figures 3(b) and (c) clearly show that the HAZ has carbide precipitates. Moreover, a very narrow shear pattern was observed outside of SZ in the TMAZ. In order to examine the effect of FSW on the micro-texture distribution, EBSD was performed in a weld cross-section of Case 4, especially within the TMAZ 
region. Figure 4(a) shows that the base metal has an averaged grain size of $\sim 4 \mu \mathrm{m}$. The high-angle grain boundaries are defined as those with misorientation angles larger than $15 \mathrm{deg}$. As observed in Figures 4(e) through (f), there was no strong texture present in the BM, HAZ, and SZ. In other words, no significant change in the micro-texture distribution between the BM and weld region was observed. Therefore, texture will not play any role in the hardness variation as observed in Figure 5. No austenite phase was observed in the weld.

Drastic variations in the microstructures within the SZ, HAZ, and BM of the FSWed experimental RAFM steel led to an inhomogeneous distribution of mechanical properties, e.g., hardness, within the different welds zones. In Case 3 (Figure 5(a)), the averaged hardness in the $\mathrm{BM}$ is about $320 \mathrm{HV}$. The SZ with a martensite microstructure reached a maximum hardness of $416 \mathrm{HV}$. A significant decrease in hardness was observed in the heat-affected zone (HAZ) with a minimum value of $242 \mathrm{HV}$. This low hardness is caused by the phase transformation to a mixture of ferrite and martensite and the precipitation of carbides. By comparing Figures 2(a) to 3(a), the faster travel rate (2.5 ipm) in Case 4 , i.e., less heat input, resulted in a smaller weld region. This is also demonstrated in Figure 5(c). The higher heat input in Case 3 also caused an overall decrease in hardness within SZ, represented by a larger area of orange and red colors in Figure 5(b) than in Figure 5(a) in SZ.
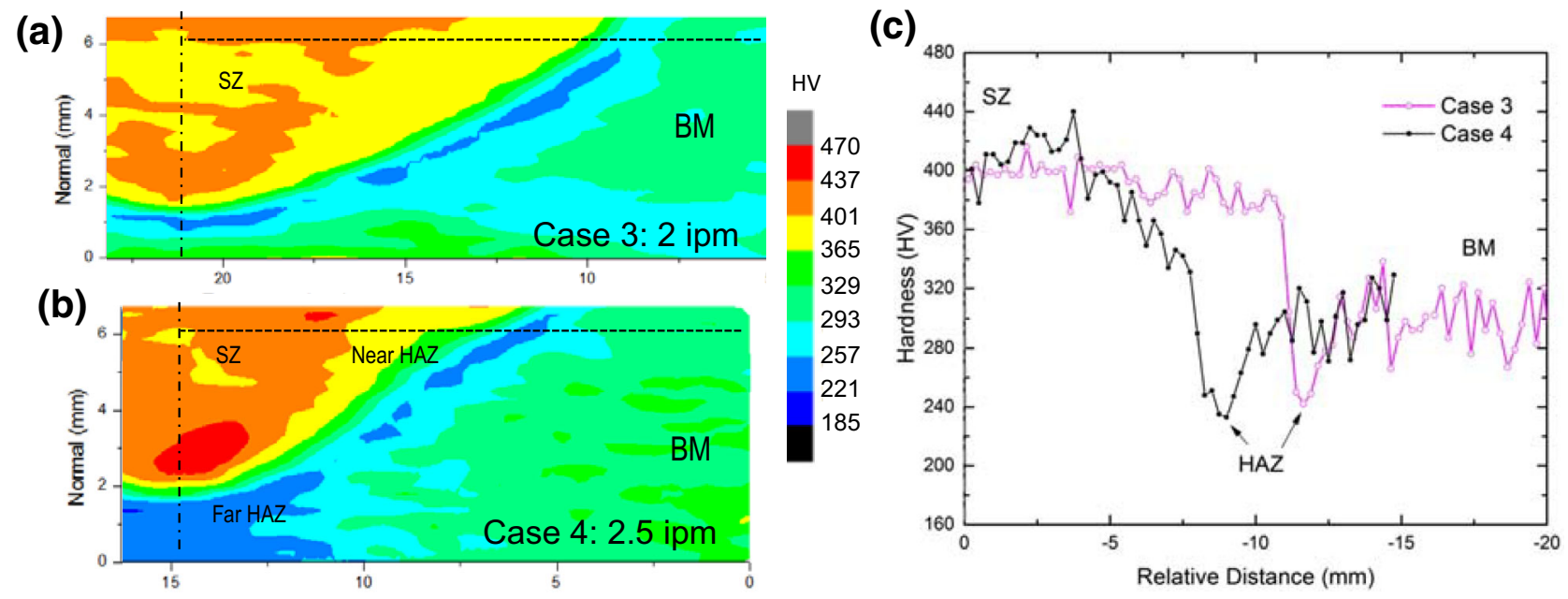

Fig. 5-Hardness mapping on the retreating side of the weld cross-sections of the experimental RAFM steels: $(a)$ Case 3 with a tool travel rate of $2 \mathrm{ipm},(b)$ Case 4 with a rate of $2.5 \mathrm{ipm}$, and (c) comparison of the hardness profiles of Case 3 and Case 4 along the black dotted line in (a) and (b).
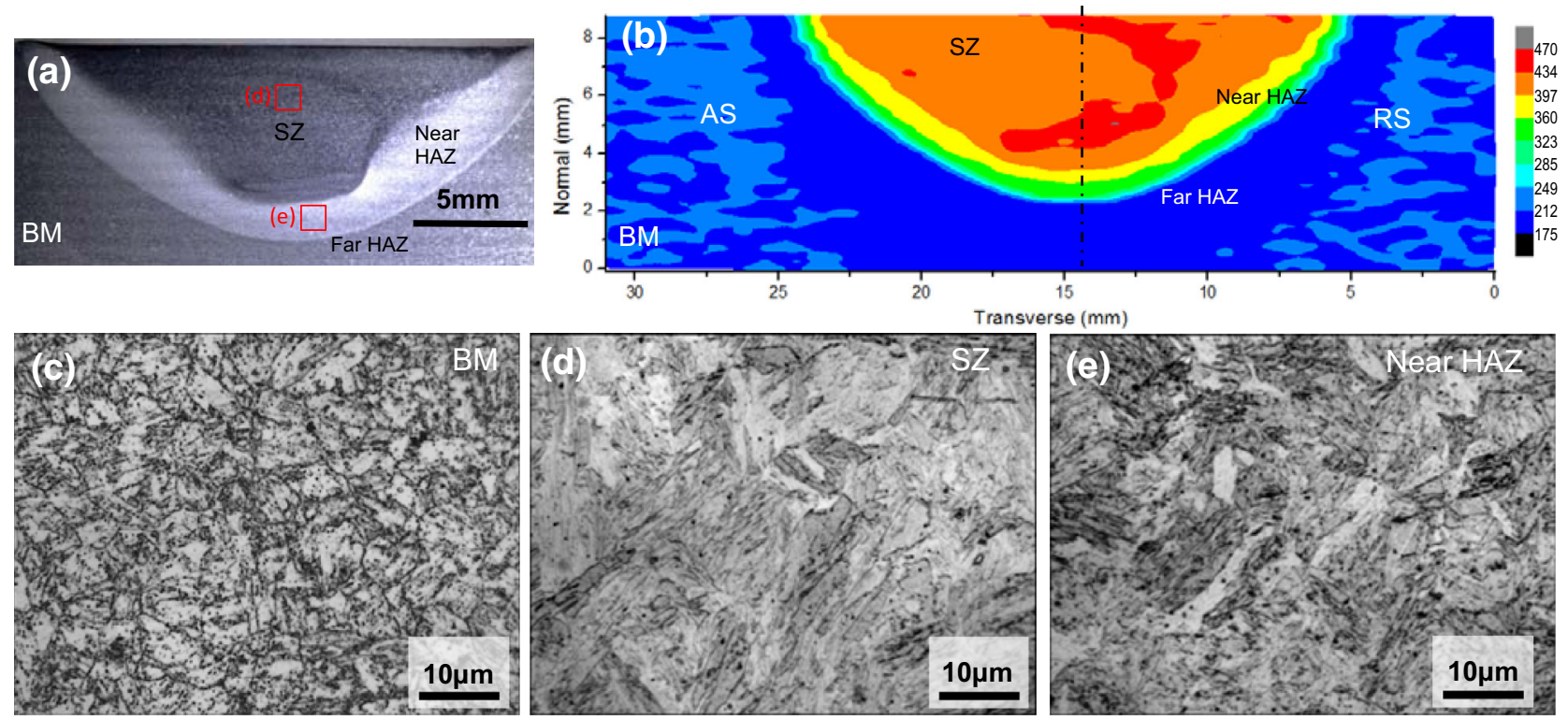

Fig. 6-FSW of EUROFER97: (a) macrograph and (b) hardness mapping of the weld cross-section; and micrographs of $(c)$ BM, $(d)$ SZ, and $(e)$ HAZ close to the SZ, namely near HAZ. 
Base Metal
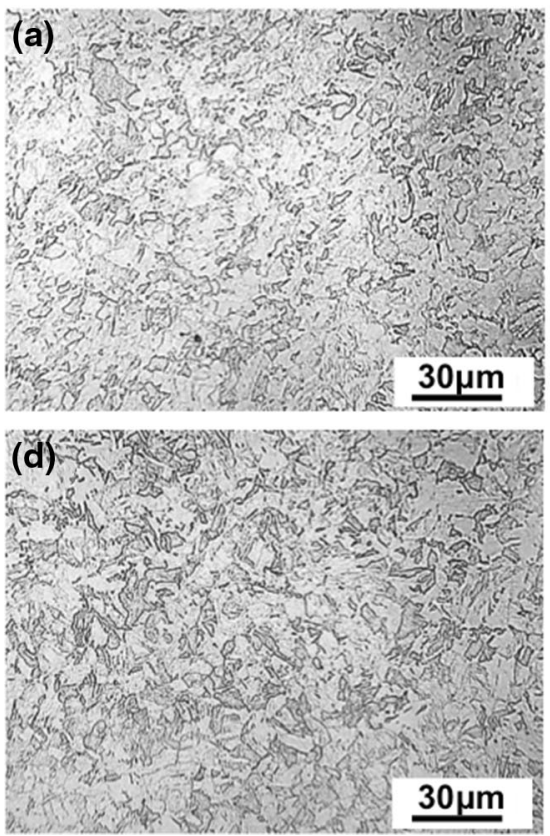

Stir Zone
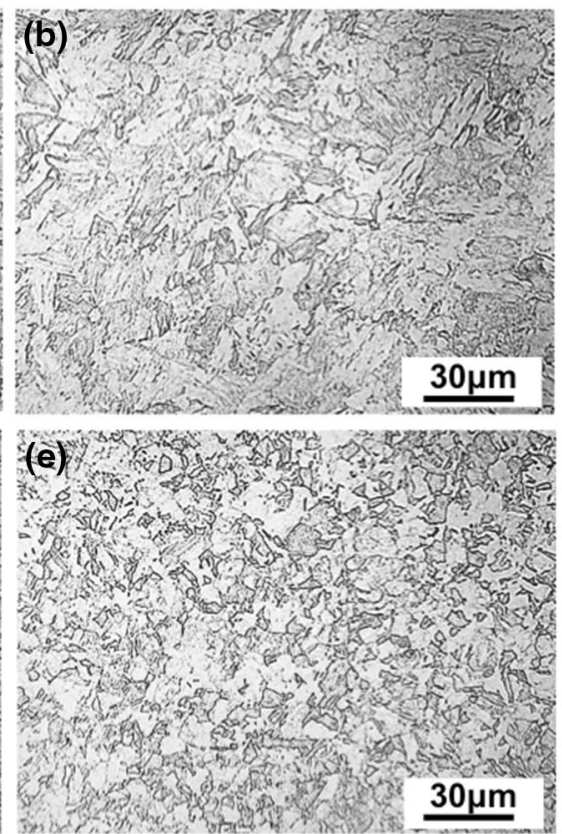

Heat-affected Zone
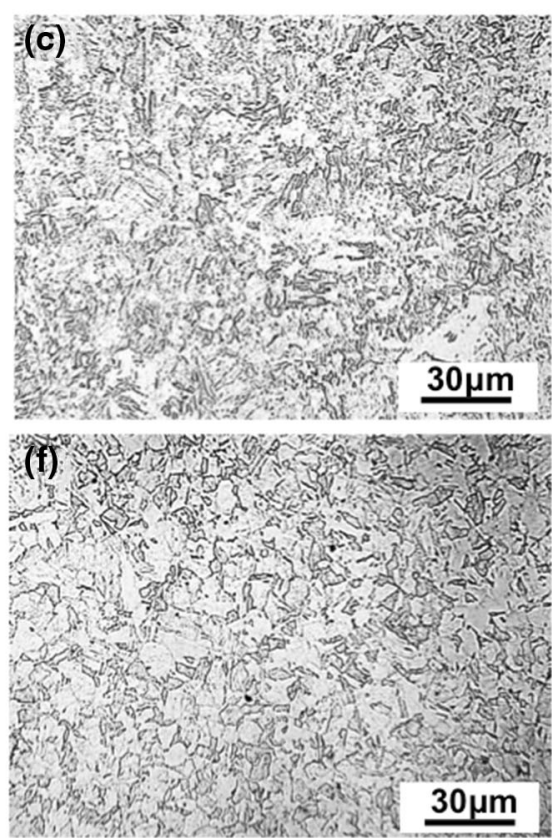

Fig. 7-Optical micrographs of the experimental RAFM steel base metal and FSW weld (Case 3 ) under PWHT conditions of $1033 \mathrm{~K}$ (760 ${ }^{\circ} \mathrm{C}$ ) for $0.5 \mathrm{~h}(a)$ through $(c)$ and re-austenization $(d)$ through $(f)$, respectively.

As shown in Figure 6(c), the initial microstructure of EUROFER97 is tempered martensite. The average grain size is about $10 \mu \mathrm{m}$. The EUROFER97 base metal average hardness is $\sim 220 \mathrm{HV}$. Figure 6(d) shows a lath martensitic microstructure present in the SZ with coarsened grains. The martensitic microstructure results in a nearly twofold increase in hardness of the SZ, as shown in Figure 6(b). The near HAZ region is more likely in the intercritical temperature range, leading to a mixture of ferrite and martensite. The dark dots in Figure 6(e) indicate the formation of carbide precipitates. Hence, a lower hardness was observed in the near HAZ compared to the SZ. The far HAZ region may have experienced temperature below $A_{1}$, which is over tempering. The decreasing peak temperature experienced by the different zones determines the gradual reduction in hardness in both the SZ and HAZ. Since high hardness would degrade toughness and creep resistance of the weld structure, PWHT is needed to restore properties of base material. ${ }^{[17]}$

\section{B. Post Weld Heat Treatment}

The microscopy examination showed that the as-welded microstructure in Case 3 (the experimental RAFM steel) has significant variation in hardness, which is not optimum for high-temperature service of this alloy. Unlike fusion welding where filler metals are used, FSW does not change the chemistry of the weld nugget. Therefore, PWHT can potentially restore the hardness of the base material.

The effect of PWHT was investigated through optical microscopic examination of the microstructural distribution and hardness mapping on cross-sections of the
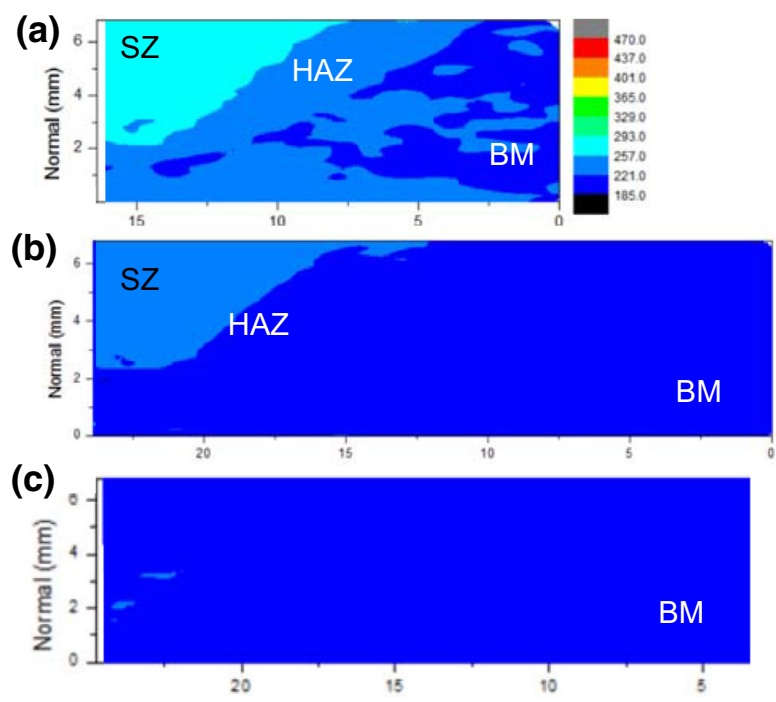

Fig. 8- Hardness mappings of the experimental RAFM steel FSW welds after PWHT at (a) $1033 \mathrm{~K}\left(760^{\circ} \mathrm{C}\right)$ for $0.5 \mathrm{~h}$, (b) $1073 \mathrm{~K}$ $\left(800{ }^{\circ} \mathrm{C}\right)$ for $0.5 \mathrm{~h}$, and $(c)$ re-austenization.

welds. Figure 2(d) illustrates that fine martensite laths and carbide precipitates are present within the HAZ of the as-welded sample. PWHT at $1033 \mathrm{~K}\left(760^{\circ} \mathrm{C}\right)$ for 0.5 hours sufficiently tempered the martensite grains within the HAZ (Figure 7(c)). However, the microstructure within SZ (Figure 7(b)) is still similar to that in the as-welded sample (Figure 2(c)), which explains the higher hardness within the SZ, as shown in Figure 8(a). Comparing Figures 8(b) through (a), raising the tempering temperature attenuates the difference between the 
hardness within SZ and BM. Figures 7(d) through (f), with a complete re-austenization process, produced uniform microstructure within the weld zones, which is identical to the base metal microstructure (Figure 7(a)). Consequently, a homogeneous hardness distribution in the weld was achieved in Case 3 (Figure 8(c)), in other words, the mechanical properties in the welded region are comparable to the base material.

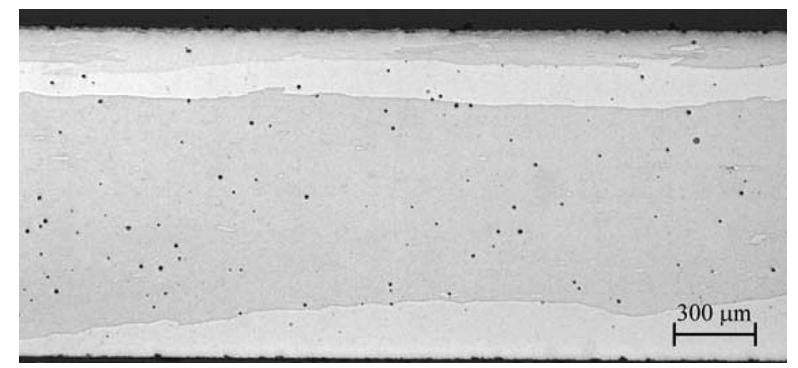

Fig. 9-Optical micrographs of the MA956 base metal.

\section{Dissimilar FSW of ODS and RAFM Steels}

Figure 9 shows that the original grains in the base metal of MA965 were very large and elongated, i.e., over several $\mathrm{mm}$ in the plane of the thin sheet. Figure 10 illustrates optical micrographs of the dissimilar weld between MA956 and EUROFER97 (Case 2 in Table I). The boundary of the SZ is highlighted by the yellow dotted line in Figure 10(a). On the retreating side of the friction stir weld, a significant amount of the MA956, which is on the top of the EUROFER97, is stirred down to the bottom of stir zone, and embedded inside the EUROFER97 by the downward stirring motion of the threaded tool pin. In Figure 10(c), the stir pattern can be clearly seen at the boundary, and a good metallurgical bond was formed at the interface between the two materials. As shown in Figures 10(b) and (d), a sharp microstructural transition in MA956 from the BM to the SZ on both the advancing and retreating sides was observed. In the SZ, the grain size of the MA956 is around $6 \mu \mathrm{m}$, as shown in Figure 10(e). Grain refinement in the SZ could have resulted from the continuous

(a)
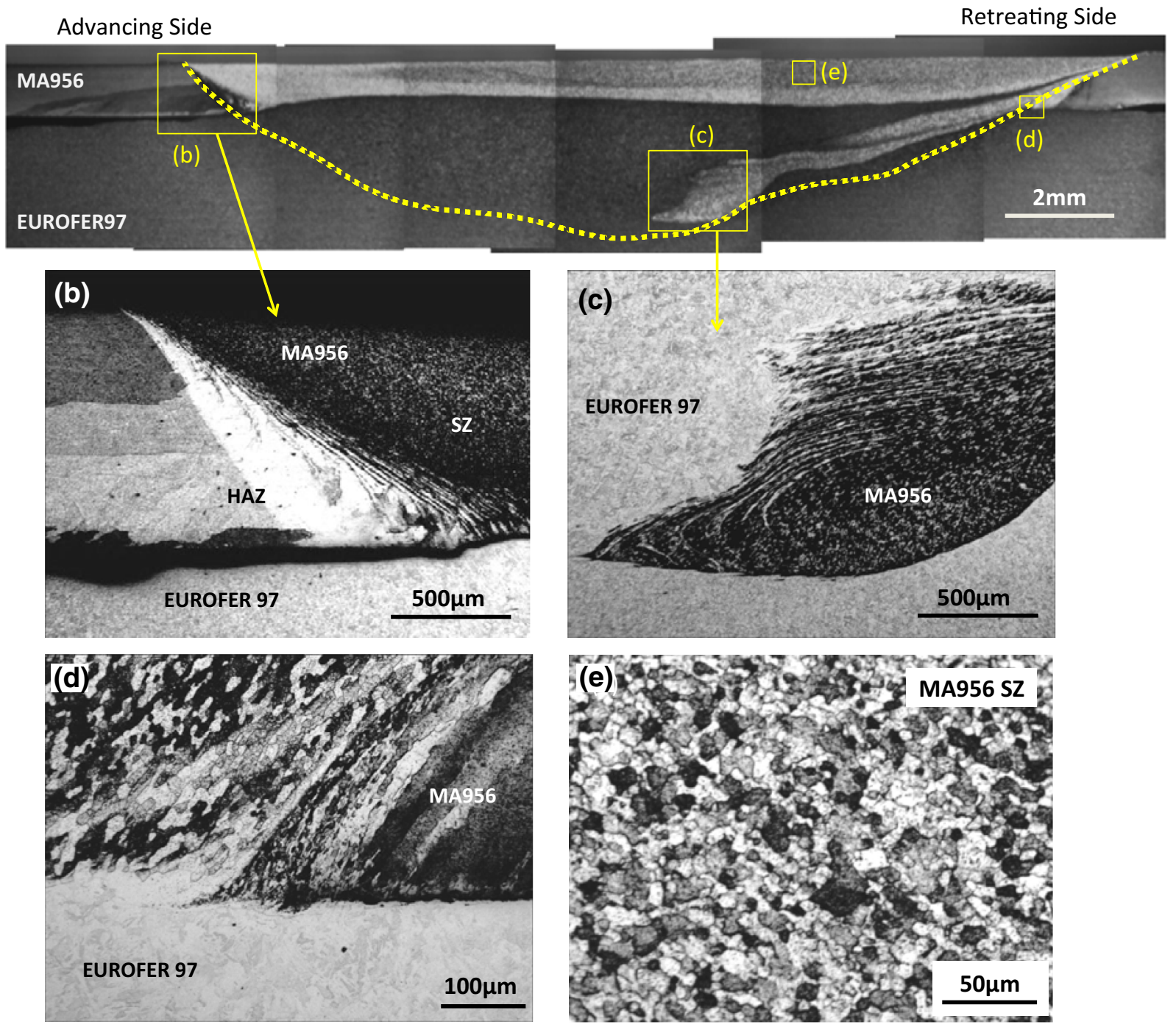

Fig. 10 - Optical micrographs of the dissimilar friction stir weld cross-section of MA956 to EUROFER97 (Case 2). 


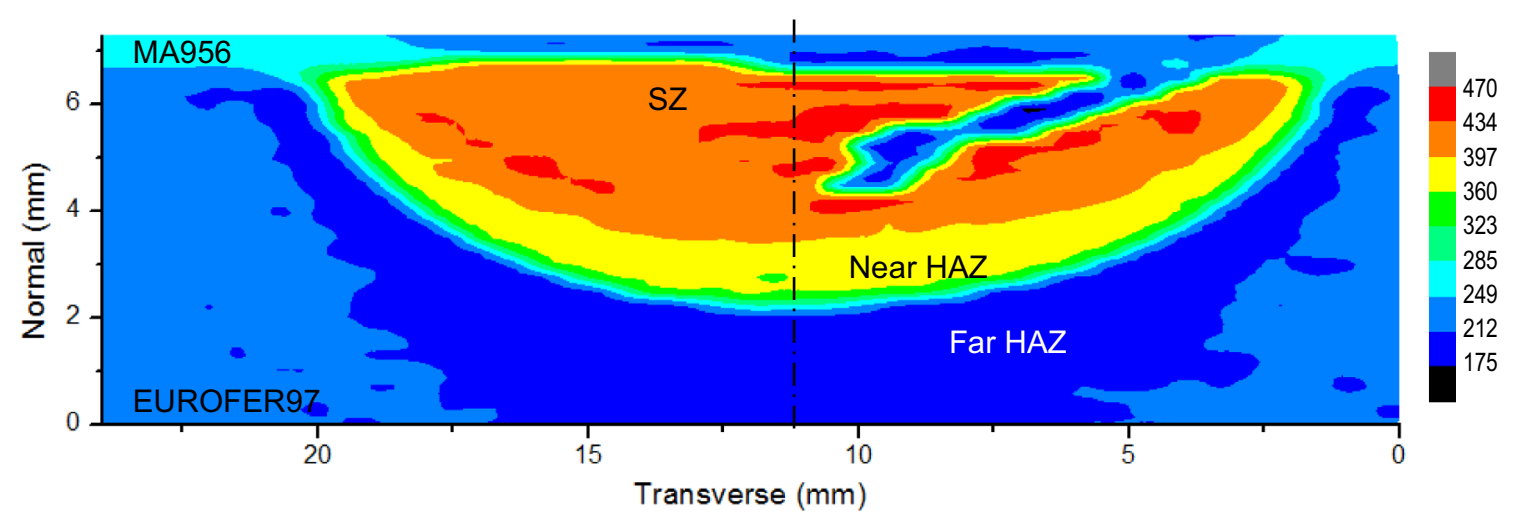

Fig. 11-Hardness mapping of the dissimilar FSW weld cross-section (Case 2).

dynamic recrystallization associated with the significant thermomechanical inputs during FSW. ${ }^{[29,30]}$ Baker et $a l .{ }^{[29]}$ also observed a pronounced abrupt change in grain size across the SZ to the TMAZ, and discussed the possibility of strain localization during tensile deformation across the weld and eventually crack nucleation at this location. Note that in Baker's work, MA956 base metal has very fine grains $(<1 \mu \mathrm{m})$ and grain coarsening occurred in the SZ due to continuous dynamic recrystallization and grain growth.

Figure 11 shows a hardness map of the weld cross-section for the dissimilar FSW weld (Case 2). The hardness of MA956 BM is about $268 \mathrm{HV}$. After FSW, hardness in the SZ of MA956 is decreased to about $200 \mathrm{HV}$, although the grain size in SZ is much smaller than the BM. There may be cold work performed in the BM of MA956, leading to the higher hardness in the BM. Note that in Baker's work, ${ }^{[29]}$ a comparable hardness of $221 \pm 4.2 \mathrm{Hv}$ was observed in SZ with a grain size diameter of $6.94 \mu \mathrm{m}$. Moreover, Wang et al. ${ }^{[30]}$ reported that the high strain rate and severe material flow during FSW of MA956 resulted in the coalescence of oxide particles through TEM examination. In a similar solid-state welding process, i.e., friction welding, Kang et al. ${ }^{[1]}$ also observed agglomeration of small yttria and larger alumina and titanium-rich particles in MA956 and concluded it was a result of high strain rate deformation. Therefore, it is possible that agglomeration of oxide particles in the MA956 contributed to the reduction in the SZ hardness.

\section{CONCLUSION}

In this work, defect-free similar and dissimilar ODS/ RAFM welds were successfully made using FSW. The following conclusions can be drawn:

1. FSW did not alter the random texture in RAFM steels;

2. Formation of a martensitic microstructure leads to a considerable increase in microhardness in the SZ, TMAZ, and near HAZ in the RAFM steel following FSW;

3. Softening in the far HAZ of the RAFM steel friction stir weld was caused by over tempering of the
BM microstructure involving the formation of carbides;

4. Increasing the welding speed led a decrease in heat input, which strongly influenced the size of weld region and the overall hardness in the SZ of the RAFM steel;

5. PWHT below A3 only partially tempered the martensite in the weld region and did not completely restore the base metal microhardness. Application of conventional base metal heat treatment schedule effectively restored the weld metal microhardness; and

6. In the dissimilar FSW of MA956 ODS alloy to EUROFER97, dynamic recrystallization occurred in the SZ of the MA956, and the microhardness of MA956 SZ was reduced. This could be caused by the agglomeration of yttria, alumina, and titanium-rich particles, or annealing if cold work was performed in the base metal.

\section{ACKNOWLEDGMENTS}

This material is based upon the work supported by the U.S. Department of Energy, Office of Fusion Energy Sciences. Research at the ORNL SHaRE Facility was supported in part by the Division of Scientific User Facilities, Office of Basic Energy Sciences, U.S. Department of Energy. The authors are grateful to Mr. D. Alan Fredrick, Dr. Yong Chae Lim, and Dr. Xinghua $\mathrm{Yu}$ for their help on the experiments, and Dr. Xizhang Chen for providing the experimental RAFM steel.

\section{REFERENCES}

1. T.S. Chou and H.K.D.H. Bhadeshia: Mater. Sci. Technol. Ser., 1993, vol. 9, pp. 890-97.

2. M.J. Fleetwood: Mater. Sci. Technol. Ser., 1986, vol. 2, pp. 117682.

3. G.R. Odette, M.J. Alinger, and B.D. Wirth: Annu. Rev. Mater. Res., 2008, vol. 38, pp. 471-503.

4. G.R. Odette and D.T. Hoelzer: JOM, 2010, vol. 62, pp. 84-92. 
5. W. Sha and H.K.D.H. Bhadeshia: Metall. Mater. Trans. A, 1994, vol. 25A, pp. 705-14.

6. M.J. Shaw: Metallurgia, 1987, vol. 54, pp. S32-33.

7. B.W. Baker and L.N. Brewer: JOM, 2014, vol. 66, pp. 2442-57.

8. Z. Feng and W. Ren: Initial Investigation on Joining ODS Alloy Using Friction Stir Welding for Gen IV Nuclear Reactor Heat Exchanger Applications, San Antonio, Texas, 2007, pp. 431-38.

9. P.D. Sketchley, P.L. Threadgill, and I.G. Wright: Mater. Sci. Eng. A Struct., 2002, vol. 329, pp. 756-62.

10. K. Shinozaki, C.Y. Kang, Y.C. Kim, M. Aritoshi, T.H. North, and Y. Nakao: Weld. J., 1997, vol. 76, pp. S289-99.

11. C.Y. Kang, T.H. North, and D.D. Perovic: Metall. Mater. Trans. A, 1996, vol. 27A, pp. 4019-29.

12. T.J. Moore and T.K. Glasgow: Weld. J., 1985, vol. 64, pp. S219-26.

13. K. Nishimoto, K. Saida, and R. Tsuduki: J. Jpn. Inst. Met., 2001, vol. 65 , pp. $756-65$.

14. T.J. Kelly: Weld. J., 1982, vol. 61, pp. S317-19.

15. D. O'Donnell: Joining of Oxide-Dispersion-Strengthened Materials, ASM Handbook, ASM International, Materials Park, $\mathrm{OH}$, 1993, pp. 1037-40.

16. L.R. Zirker, J.H. Bottcher, S. Shikakura, C.L. Tsai, and M.L. Hamilton: International Conference on Fast Reactor Systems and Fuel Cycles, Kyoto, Japan, 1991.

17. P. Aubert, F. Tavassoli, M. Rieth, E. Diegele, and Y. Poitevin: $J$. Nucl. Mater., 2011, vol. 417, pp. 43-50.

18. R.J. Kurtz, A. Alamo, E. Lucon, Q. Huang, S. Jitsukawa, A. Kimura, R.L. Klueh, G.R. Odette, C. Petersen, M.A. Sokolov, P. Spatig, and J.W. Rensman: J. Nucl. Mater., 2009, vols. 386-388, pp. 411-17.

19. H. Serizawa, S. Nakamura, M. Tanaka, Y. Kawahito, H. Tanigawa, and S. Katayama: J. Nucl. Mater., 2011, vol. 417, pp. 55-58.

20. B. Raj and T. Jayakumar: J. Nucl. Mater., 2011, vol. 417, pp. 72-76.

21. G Srinivasan, B Arivazhagan, SK Albert, and AK Bhaduri: Fusion Eng. Des., 2011, vol. 86, pp. 446-451.

22. H. Tanigawa, T. Hirose, K. Shiba, B.R. Kasada, E. Wakaia, H. Serizawa, Y. Kawahito, S. Jitsukawa, A. Kimura, Y. Kohno, A.
Kohyama, S. Katayama, H. Mori, K. Nishimoto, R.L. Klueh, M.A. Sokolov, R.E. Stoller, and S.J. Zinkle: Fusion Eng. Des., 2008, vol. 83, pp. 1471-76.

23. H. Tanigawa, K. Shiba, A. Moeslang, R.E. Stoller, R. Lindau, M.A. Sokolov, G.R. Odette, R.J. Kurtz, and S. Jitsukawa: J. Nucl. Mater., 2011, vol. 417, pp. 9-15.

24. H. Tanigawa, K. Shiba, M.A. Sokolov, and R.L. Klueh: Fusion Sci. Technol., 2003, vol. 44, pp. 206-10.

25. J. Gould, T. Linert, and Z. Feng: SAE Trans. J. Mater. Manuf., 1998, vol. 107, pp. 1093-1100.

26. Z. Feng: EERE Vehicle Technology Annual Progress Reports for High Strength Weight Reduction Materials, 2005.

27. R.S. Mishra and Z.Y. Ma: Mater. Sci. Eng. R, 2005, vol. 50, pp. 178.

28. C.L. Chen, P. Wang, and G.J. Tatlock: Mater. High Temp., 2009, vol. 26, pp. 299-303.

29. B.W. Baker, E.S.K. Menon, T.R. McNelley, L.N. Brewer, B. EL-Dasher, J.C. Farmer, S.G. Torres, M. Mahoney, and S. Sanderson: Metall. Mater. Trans. E, 2014, vol. 1E, pp. 318-30.

30. J.Y. Wang, W. Yuan, R.S. Mishra, and I. Charit: J. Nucl. Mater., 2013, vol. 432, pp. 274-80.

31. S. Jitsukawa, A. Kimura, A. Kohyama, R.L. Klueh, A.A. Tavassoli, B. van der Schaaf, G.R. Odette, J.W. Rensman, M. Victoria, and C. Petersen: J. Nucl. Mater., 2004, vol. 329, pp. 3946.

32. S. Jitsukawa, M. Tamura, B. van der Schaaf, R.L. Klueh, A. Alamo, C. Petersen, M. Schirra, P. Spaetig, G.R. Odette, A.A. Tavassoli, K. Shiba, A. Kohyama, and A. Kimura: J. Nucl. Mater., 2002, vol. 307, pp. 179-86.

33. M.J. Alinger, G.R. Odette, and D.T. Hoelzer: Acta Mater., 2009, vol. 57, pp. 392-406.

34. V Voort: Metallography Principles and Practice, ASM International, New York, 1999.

35. N. Inoue, T. Muroga, A. Nishimura, and O. Motojima: J. Nucl. Mater., 1998, vol. 258, pp. 1248-52. 